cen fond in the noighbourbood of the rentriales

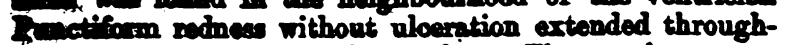
The the entive length of the trachea. The cesophagus was File, and perfeotily healthy throughout. The cervical por Fion of the left por wagum was manifactly exlarged The heart was palo, flabby, and its tisesue readily lacerable. The liver was in a state of yellow atrophy of Lebert; and this atrophy was suspected during life, from the extended abeence of the normal hepatic sound, and want of resistance to the percussing finger. The crocum was greatly distended with air, as were also in a less degree the colon and small intestines. The kidneys were large and flabby, but no minute examination was made. The remaining organs were, 80 far as was ascertained, healthy. Neither the brain nor medulla spinalis were examined. A most careful and prolonged microscopic examination of the diseased portions of the lungs was made, including both the solid framework and expressed fluid. Numberless and well-marked cells; caudate, spindle-shaped, ovate mother cells, with large and well-defined nuclei; melanotic cells, exhibiting well-marked molecular movement; fat-globules; compound granular cells; fibres; granules; in a word, all those elements which, taken collectively, characterise malignant growth, placed the nature of the case beyond doubt.

REMarks. The case detailed undoubtedly offers many peculiarities, and is perhaps in some respects unique. Viewed in its several phases, it presented an affinity more or less strong to several different diseases. At one time, the symptoms justified to some extent the suspicion of aortic aneurism. There existed deep-seated dysphagia, cough, hoarseness, stridor, paroxysmal difficulty of breathing, with absence of the physical signs of lung disease: but this view was negatived upon the following grounds. The dysphagia was neither constant nor progressive; there existed none of the physical signs of aneurism; the stridor was from above, not from below; while the vital symptoms scarcely resembled in any respect those of the disease in question. To laryngeal phthisis the affection bore the closest resemblance. There may be adduced in evidence cough, hoarseness, and other laryngeal symptoms ; muco-puriform expectoration, accelerated pulse and breathing, progressive emaciation, nocturnal perspirations, diarrhoea, pain in the region of the ileo-creal valve, debility, febrile excitement, and the urine loaded with urates; while the absence of detectable physical signs did not negative this view; but, had those of excavation in the upper part of the left lung been recognised during life, it would perhaps have rendered such diagnosis almost certain. It may be proper to mention here that possibly the softening process did not commence until within a few days before death, when, owing to the extreme distress of the patient, physical exploration was impossible: at all events, it was not detected in the very many examinations made at an earlier period.

It is hardly necessary to do more than advert to the similarity, with regard to the local symptoms, between this affection and cynanche laryngea, both idiopathic and specific. Difficulty of swallowing is well known to be common to laryngeal disease in general; but as in this case such disease bore no proportion to the inability to swallow, and the csophagus was perfectly normal in structure, the symptom deserves attention, when it is borne in mind that it was noticed by Morgagni also in a case of cancer of the lung (Letter XXII).

In reviewing the various symptoms presented by this case, I would inquire whether they are sufficiently explained by the degeneration which the larynx and the pulmonary structure had undergone;"or should they rather be regarded as a result of that sustained by the left par ragum?

Of the degenerations of the lung and trachea, again, which had the initiative? Was the early affection of the thrast the result of latent disease of the lung; or did the hryngeal affection, by inducing irritation of the pulmonary tiseue, develope cancerous disease in a predisposed subject? But cpart from this, it may perhaps be aecerted, without fear of contradiction, that, in the actual state of science, cancerous may occasionally so closely resemble tubenculous cachexis that the differential diagnosis of the two affections cannot with certainty be established.

London, October 1864.

\section{CASE OF SCARLATINA:}

DEATH BY ARTERIAL HEXORHHAGE FROM ULCERATION OF THE PHARYNX. (LESTOY OF ASCENDIYG PHARYNGEAL OR IXTERYAL CAROTID ABTERY?)

By FRFDERICK JAMES BROWN, M.D.

Is the Medical Gazette for November 21, 1851. I reported a death by venous hremorrhage in scarlatina. In that case, the child, aged 5 years, was ill twenty-two days; had phlebitic cervical abscesses, on each side, for twelve days ; and died by hæmorrhage from a large vein, recurring several times during twenty hours. No trace of the external jugular vein could be found. No ulceration could be detected in the internal jugular vein, although it was bathed in pus.

The present case was one that occurred in the family of a labourer in the Dockyard at Chatham. 'The locality was at the base of the lines, but much above the level of the rest of the town, and not particularly unhealthy.

I will give a summary of the interesting points in the cases that occurred in this family, and will then proceed to detail the particulars of the fatal case.

1. Mary Ann Gammon, aged $9 \frac{1}{2}$ years.

July 2d, 1852. She was seized with scarlatina, and had the disease severely. She had phlebitic abscesses in the neck, on each side.

July 27 th. The kidneys were affected. She had bloody urine, and sweiling of the face.

July 30th. There was epistaxis.

Aug. 31. She had serous vomiting and purging, closely resembling cholera.

Sept. 2nd. She was discharged cured. There was no general dropsy.

2. Edmund, aged 18 months, on

July 7 th, was seized with scarlatina.

Aug. 30th. Diarrhœa and lichen appeared.

Sept. 2nd. He was discharged cured. He had no dropsy; and had the disease sharply.

3. Clara, aged 7 years, on

July 12 th, was seized with scarlatina.

Aug. 2nd. She died. (See the details.)

4. Louisa, aged 5 years, on

July 15th, was seized with scarlatina. She had large glandular swellings in the neck, which did not suppurate.

Aug. 6th. Anasarca and ascites appeared; they were preceded by renal affection, and lichen.

Aug. 30. There was a fresh eruption of lichen.

Sept. 2 nd. She was discharged cured.

5. Mr. Exckiel Gammon, aged 39 years.

July 19th. He was seized with scarlatina, and had the disease mildly.

Aug. 2nd. Anasarca was presønt.

Aug. 20th. He was discharged cured.

The treatment consisted principally in the exhibition of beef-tea, ammonia, and brandy; aud in the syringing of the fauces with a weak solution of nitrate of silver. A glass syringe was introduced over the tongue, and the throat was injected once a day. One teaspoonful of a solution of nitrate of silver (two scruples to the ounce), was put into a wineglassful of cold water, and used as explained. Leeches were applied to the loins when the kidneys gave rise to symptoms.

Cise. Clara Gammon, aged 7 years and 5 months, was seized with scarlatina on the 12th July, 1852.

July 13th. The rash was well out.

July 16th. The pulse was weak. There was restlessness, and occasional delirium; the rash was vivid. Ammonia and brandy were ordered, with beef-tea. 
July 17th. The throst was very sore; the stin was still red; the restlesencess continued. The same treatment was continued; and she was ordered to have quinine in Epsom calts mixture.

July 18th. She passed a bad night. There was occar sional delirium. The skin was dusky; there was a diphtheritic pellicle on the fauces; deglutition was difficult. The throst was syringed.

July 19th. The mental faculties were oppressed.

July 20th. The throat was better; the pulse was steady ; the skin less dusky; the bowels were confined; the right side of the face was flaccid, as if paralysed; voluntary power was not abrogated. Castor oil was ordered.

July 21st. She appeared better; the skin was rough and chip-like. There was a discharge from the right ear.

\section{July 22nd. The discharge had ceased.}

July 23rd. The patient had convulsive fits last night, preceded by pains over the whole body. The pulse was quiet; the urine was abundant. She lay in a placid state.

July 24th. Convulsive twitchings occurred in the night, and some to-day, of a less severe kind. Fretfulness preceded the convulsive moments. There was paralysis of the right side of the face, and of the right eyelids. There was considerable swelling on the right side of the neck. The tongue was becoming clean; the urine was free. The head was ordered to be shaved, and two leeches to be applied to the temple. The treatment was continued; and she was directed to have porter in addition.

July 25 th. She was relieved by the leeching, and seemed better. There had been no more convulsions. The countenance was almost natural.

July 26th. There was a large abscess on the right side of the neck. I made an incision into it. A small quantity only of pus escaped, in consequence of the insufficiency of the incision.

July 27th. There was a more free escape of pus.

July 28th. Both sides of the neck were swelled. The distortions of the face were strongly marked. The health was improving.

July 29th. She took food well. Bright blood came from her nose and throat, to the amount of three-quarters of a pint, as far as could be judged.

July 30th. There was a free discharge of pus from the right side of the neck.

July 31st. There was bright bleeding, at 8 P.M., from nose, estimated at one pint. It produced syncope.

August 1st. There was no recurrence of hæmorrhage. She seemed better, and ate cold bread and milk.

Aug. 2nd. She passed a good night. At a quarter past 8 A.M., hæmorrhage, "to the amount of a quart", suddenly occurred. She died in five minutes.

Examination of BoDr, twenty hours after death: weather warm and close. The head was most completely forgotten: I was thinking so much about the source of hæmorrhage whilst dissecting the neck, that I forgot to examine the brain and the portio dura nerve. Rigor mortis was present. The body was fat. The left side of the neck was distended by an unopened abscess. The right side of the neck was flaccid, because of the escape of pus. The right sterno-mastoid muscle was softened in its anterior border at the upper part. The parotid and submaxillary glands were unaffected on the right side; those on the left side were not examined. The pus was not diffused in the neck, but had passed from beneath the deep fascia below the angle of the jaw through an ulcerated aperture, and had so escaped through the incision in the skin. The pouch beneath the fascia was capable of containing three or four chesnuts; and pus, equal in amount to a pea, was found in the course of the lingual artery; but the vessel was not affected. On opening into the mouth from below, an ulcerated aperture was fcund in the pharynx, on the right side, of the size of a crowquill. Communication was thus effected with a pouch of matter situated just externally to the superior conetrictor muscle, and in the immodinte vicinity of the internal carotid and ascending pher

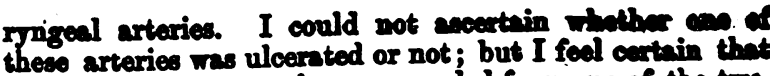
the hemorrhage must have proceeded from one of the tro. Both jugular veins were sound. The pharynx and stomach contained sir or eight ounces of blood; and there was blood in the larynx and bronchi. The lungs were white and anmic. The heart was healthy. There was rather more serum in the pericardium than usual. The liver was pale, but healthy. Bile was present in the gall-bladder. The spleen was healthy, but rather soft. The stomach and intestines were healthy: the stomach was large in size. The right kidney was congested, and the striæ enlarged: blood escaped on section of it. The strim were enlarged in the left kidney. The urinary bladder was full. The size of the oraries was that of French beans.

Chatham, October 1854.

[Several cases are on record very similar to that related by Dr. Brown, in which abscess in the neck from scarlatina has produced fatal hæmorrhage from ulceration of a cervical vessel. The London Journal of Medicine for August 1850 contained the report of a case by Dr. R. J. Hale; and the same journal for April 1851, gave an abstract of a case reported by Drs. Depéret Muret and Boulland in the Union Médicale for August 24th, 1850. EDITor.]

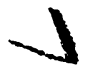

\section{CASE OF FATAL STRANGULATED HERNIA, MASKED BY A TUMOUR IN THE GROIN.}

By JOHN WINDSOR, F.R.C.S., Senior Surgeon of the Manchester Eye Hospital.

In the Association Jorknar for the current month (October 13 th, 1854 , p. 923), a case is related by Mr. J. D. Brown, of strangulated hernia in a female, masked by an enlarged gland, but which terminated favourably after an operation. Reference is made in the same paper to 8 somewhat similar case, also occurring in a female, and described by Dr. J. Ridge in the Associs TION Jouknsu (p. 468) of the present year. I am induced by the perusal of these cases to refer to a ncarly similar one in a male, which occurred to me in the early part of this year. As I did not record the case in detail at the time, I will state the circumstances attending it very briefly.

CAsz. On the 6th of March, 1854, I was requested by his son to visit John Horsfield, aged 62, residing at Whitefield, a few miles from Manchester, on the Bury road. I went almost immediately; but he had died about half-past three, P.M., before my arrival.

I ascertained the following particulars: viz., that, eight days before, on Sunday morning, the 26th of February, after a very straining costive evacuation from the bowels, he was seized with pain in the lower part of the abdomen, sickness, and vomiting. These symptoms, with constipation of the bowels, continuing, a neighbouring surgeon was called in, who used a variety of means without affording any decided relief. The tumour or chronic inguinal enlargement was examined, but no hernial descent could be detected; it was therefore supposed that no operation was indicated, and the case progressed to its fatal termination.

On one occasion, about twelve months previously, I had an opportunity of examining the inguinal tumour, which was of a somewhat dusky colour, projecting immediately under the integuments, and of about the size of a rather large pullet's egg. It was not attended with much pain or inconvenience.

Permission being now granted, about two hours after his death, to examine the parts, I found the tumour composed of apparently degenerated glandular substance, most like friable decajed cheese, and of a brownish colour, without any appearance of vascularity or organisation. On eramining behind this if there might be any hernial protruvion, I found outaide the external ring a lenotlo of 